\title{
EREBEA
}

\author{
Revista de Humanidades \\ y Ciencias Sociales \\ Núm. 8 (2018), pp. 113-134 \\ ISSN: 0214-0691
}

\section{UNA MIRADA INDISCRETA. LA COSMOGONÍA MARISMEÑA DE SAN JuAN Del Puerto (Huelva) a través de una Visión ETNOHISTÓRICA}

\author{
Juan Carlos Romero-Villadóniga \\ Universidad de Huelva*
}

RESUMEN

Cuando el antropólogo se enfrenta al reto del discernimiento de la identidad en una comunidad compleja, muchas son las interrogantes que se le plantean. Cuestiones las cuales sólo pueden ser atendidas desde una asunción del método moriniano y a través de un análisis diacrónico de la sociedad, de ahí la importancia de abogar por la etnohistoria como forma de estudiar en el tiempo la identidad colectiva presente de los pueblos. En el presente artículo se analizan, a grandes rasgos, algunas de las pautas culturales de San Juan del Puerto por medio de un viaje antropológico en el tiempo, incidiendo en las ligazones existentes con el entorno marismeño próximo, el cual forma parte intrínseca de la peculiar idiosincrasia y la cosmogonía sanjuanera.

\footnotetext{
Palabras Clave

Identidad; complejidad; etnohistoria; diacronía; lugar.
}

Fecha de recepción: 11 de oct. de 2018

Fecha de aceptación: 1 de nov. de 2018

* Grupo HUM 556 "Mundialización e Identidad”
ABSTRACT

When the anthropologist faces the challenge of discerning the identity of a complex community, there are many questions that are asked. Issues which can only be met from an assumption of moriniano method and through a diachronic analysis of society, hence the importance of advocating ethnohistory as a way of studying this time the collective identity of peoples. In this article we analyze broadly, some of the cultural patterns of San Juan del Puerto through an anthropological journey through time, focusing on existing bindings to the next marshy environment, which is an intrinsic part of the peculiar idiosyncrasy and cosmogony.

\section{KeYwORDS \\ Identity; complexity; ethnohistory; diachrony place.}


LA IMPORTANCIA DE LA ETNOHISTORIA EN LA APRECIACIÓN DEL LUGAR. BUCEANDO A TRAVÉS DEL TIEMPO.

Dije: buscaré lo que es humilde y pondré las raíces de mi identidad allí: todos los días despertaré y encontraré lo humilde cerca ${ }^{1}$.

Sin duda alguna, la búsqueda de la identidad es uno de los más apasionantes retos del ser humano. Con relativa frecuencia se recurre a la literatura más prosaica para intentar poner algo de cordura en un concepto, ya de por sí, complejo. La actual lógica racional-cartesiana-mecanicista-newtoniana no ha sido capaz, en ningún momento, de poder siquiera acercarse a la definición holística del término. Con un método simplista alejado de la realidad empírica, se esfuerza en denostados cuerpos teóricos los cuales no hacen sino hacer evidente su incapacidad explicativa.

Por esta razón, se hace necesario una amplitud de miras metodológicas y programáticas para poder enfrentarse con absoluta seguridad a un planteamiento de estas características. Cuando Ilya Prigogine ${ }^{2}$ hablaba de los desequilibros de las estructuras, precisamente estaba haciendo, sin saberlo, una gran contribución a las Ciencias Sociales. Nada es explicable si no es desde la asunción de la complejidad como fórmula de conocimiento. Autores como Morín ${ }^{3}$ o Capra ${ }^{4}$, han puesto en cuestión modelos los cuales no hacen sino encorsetar cualquier fenómeno empíricamente observable.

De esta forma, analizar al ser humano es aprender a conocerlo desde una perspectiva eco-físico-bio-emo-mentalo-noológica ${ }^{5}$, atendiendo en todo momento las conexiones y nudos gordianos que se establecen entre cada una de sus partes ${ }^{6}$, desde una perspectiva multidisciplinar e integral, como apunta Carmelo Lisón ${ }^{7}$.

1 A. Randolph Ammons, The Selected Poems: 1951-1977. Washington, D.C.: Expanded Edition, 1986.

2 I. Prigogine. Las Leyes del caos. Barcelona: Ed. Crítica, 1997.

3 E. Morín. Introducción al pensamiento complejo. México, D. F.: Editorial Gedisa, 2004.

4 F. Capra. Las conexiones ocultas. Barcelona: Anagrama, 2003.

5 E. Morin. Ciencia con conciencia. Barcelona: Anthropos, 1984.

6 Capra, Las conexiones...

7 C. Lisón. Antropología integral. Ensayos teóricos. Madrid: Editorial Universitaria Ramón 
No se puede conocer la identidad del individuo si es sesgado del medio físico y humano en el que opera culturalmente, como tampoco sin recurrir, cuán viajero en el tiempo, al juego diacrónico y sincrónico en un continuo ir y venir, de ahí la importancia de la etnohistoria como una herramienta útil para el conocimiento de pautas y rasgos en culturas presentes.

Para autores como Rodríguez y Aguirre, "la etnohistoria es un método de la Antropología Cultural a través del cual se estudia la cultura de sociedades pretéritas en base a documentos históricos, asi como la identidad colectiva de los pueblos", siendo los documentos y registros históricos, informantes privilegiados que proporcionarán la información necesaria acerca de los procesos de cambio cultural. Es decir, la etnohistoria, en palabras de Herkovits y Aguirre' ${ }^{9}$, sería aquella que trata a los papeles y todo tipo de documentos como informantes ${ }^{10}$, de tal forma que su método conduce a tratarlos como conectores de un pasado que dejan patente, por escrito, el legado patrimonial de un sentimiento colectivo.

En contraste con esta apreciación, propuestas como las de Cohn o Valcárcel, puntualizan acerca del objetivo de la etnohistoria en la investigación antropológica. Sea como fuere, lo que está fuera de toda duda es el rol que va a jugar, pues se va a convertir en el recurso innato del antropólogo a la hora de conocer la evolución cultural de sociedades, tanto simples como complejas, de una forma diacrónica, de ahí que haya entrado en un espacio acotado normalmente para otras disciplinas.

No obstante, a pesar de esta aparente "ocupación”, los campos de análisis van ser muy diferentes, ya que el objeto de la etnohistoria va a ser el conocimiento del microcosmos, de la cotidianeidad social, huyendo de los grandes momentos estructurales o hitos. El antropólogo se sumerge en el estudio diacrónico de las sociedades, para poder explicar los cambios y transformaciones que se operarán a lo largo del espacio y tiempo.

Esta necesidad de estudiar diacrónicamente las sociedades, parte del propio objeto de estudio antropológico, la formación de las identidades. En este sentido, Rodríguez y Aguirre" señalan cómo "el estudio de la identidad debe partir de un estudio histórico de la sociedad objeto de análisis. Este pasado configura una serie de patrones culturales identitarios, asi como pueden generar identidades futuras".

De esta forma, se debe comenzar de una concepción de la etnohistoria modificada de los parámetros academicistas anteriores, no considerándose como

Areces, 2010.

8 M. Rodríguez. y A Aguirre. "Etnohistoria y etnobiografía”. En Angel Aguirre (ed): Cultura e identidad cultural. Barcelona, ed. Bardenas, 1997, pp. 60-65. 28-31.

9 A. Aguirre. "Inquisición, molinos y molineros". En Molinum no 37, noviembre, 2012, pp.

10 A. Jiménez. "Sobre el concepto de etnohistoria". En Alfredo Jiménez (ed.) Primera reunión de antropólogos españoles. Sevilla, Universidad de Sevilla, 1974, pp. 91-105

11 Rodríguez y Aguirre, Etnohistoria y etnobiografía... 
una metodología exclusiva para el conocimiento de poblaciones indígenas, sino como "una lectura antropológica de fuentes históricas", para el discernimiento de los tiempos presentes, en un intento de atisbar las totalidades socioculturales integradas en un marco espacial y temporal tanto sincrónico como diacrónico.

Desde una perspectiva más amplia, Wilde ${ }^{12}$ hace ver cómo la identidad de los pueblos "respondería a condiciones socioeconómicas, politicas e históricas especificas. La orientación que han de tomar los estudios sobre identidad en los próximos años, es entonces la de analizar procesos complejos con categorias más flexibles y que a veces no reniegan de su ambigüedad"13.

La etnohistoria permite, por tanto, como expresa Auge ${ }^{14}$, el conocimiento de rasgos identitarios de sociedades pasadas, a partir de la elección de escalas temporales y espaciales macro y micro, ya que "si el espacio es la materia prima de la antropología, se trata aqui de un espacio histórico, y si el tiempo es la materia prima de la historia, se trata de un tiempo localizado y, en este sentido, un tiempo antropológico" 15 .

Por esta razón, para intentar conocer pautas identitarias en poblaciones concretas, debe uno zambullirse en un tiempo y espacio localizado, para la creación de las conexiones pasadas, presentes, y quien sabe si futuras.

\title{
Rasgos identitatios marismeños de San Juan del Puerto a lo largo de la EdAd MOderna.
}

\author{
"Si entre las casas, las calles y los grupos \\ de sus habitantes no existiera más que una \\ relación accidental y de corta duración, los hombres \\ podrian destruir sus viviendas, su barrio, su ciudad, \\ y reconstruir en el mismo lugar una diferente, \\ siguiendo una idea diversa: pero si las piedras \\ se dejan transportar, no es tan fácil modificar \\ las relaciones que se han establecido entre las \\ piedras y los hombres"16
}

12 G. Wilde. "La problemática de la identidad en el cruce de perspectivas entre antropología e historia. Reflexiones desde el campo de la etnohistoria". En Ciudad Virtual de Antropología y Arqueología . Disponible en http://www. naya.org.ar. Consultado el 13/09/2012.

13 M. Castells. El Poder de la Identidad. 2 vol. Madrid: Ed. Alianza, 1997.

$14 \mathrm{M}$. Auge. El espacio histórico de la antropología y el tiempo antropológico de la historia. Hacia una antropología de los mundos contemporáneos. Barcelona: Ed. Gedisa., 1995. 20.

15 Auge. El espacio histórico de la antropología y el tiempo antropológico de la historia, pp.

16 M. Halbwachs. "Fragmentos de la Memoria colectiva", en Revista de Cultura Psicológica año 1, no 1, México DF, México: UNAM, 1991. Halbwachs está considerado como uno de los principales delimitadores conceptuales de la memoria, pudiendo haber llegado a unos niveles aún 
En las proximidades a la desembocadura del río Tinto, vecino de la capital onubense, San Juan del Puerto es un enclave de poco más de 5400 hectáreas repartidas en dos sectores territoriales. En relación con las poblaciones del entorno, su término municipal va a resultar secundario teniendo, eso sí, una amplia porción de tierras en marismas próximas al río, lo cual indica su clara vocación marismeña. Pasear por su término municipal es visualizar dos realidades distintas. Por un lado, una pequeña pero fértil campińa destinada a la cerealicultura básicamente, mientras que por otro encuentra su máxima extensión en los humadales y áreas de marismas, las cuales se hallan bañadas por el río.

Desde su fundación en 1468, y quizás en momentos anteriores, cuando no era más que un pequeño asentamiento de pescadores, San Juan del Puerto va a vivir en estrecha comunión con su medio circundante, especialmente el entorno marismeńo. La Carta Puebla otorgada por D Juan de Guzmán y su hijo primogénito D. Enrique de Guzmán ${ }^{17}$ ya establecen la ligazón intrínseca con la que va a ser reconocida la villa en sus primeros siglos de existencia, cuando comenta: "porque algunas personas de fuera de nuestra tierra e señorio quieren venir nuevamente a fazer poblazón e asiento e bivienda en el puerto de San Juan, junto con el rio de Saltes" 18 .

En la Carta se reconocerá el derecho a ocupar el terreno que actualmente tiene la población. A cambio se les proporcionarán tierras comunales (dehesas), tierras para viñas, y los medios necesarios para la construcción y reparación de navíos ${ }^{19}$. Gracias a estos privilegios fueron llegando gradualmente vecinos que se fueron afincando en las proximidades al río Tinto, llegando a contabilizarse hasta 238 a los pocos ańos de su fundación ${ }^{20}$. La causa de esta exitosa repoblación radicará según autores como Mora Negro ${ }^{21}$ en su "fértil campiña y el comercio de su ría".

Esta importancia de la ría en el desarrollo sanjuanero de los primeros tiempos va a estar fuera de toda duda, como lo atestiguan los diferentes decretos y privilegios concedidos en sus primeros tiempos por la familia de los Media Sidonia.

más complejos de no haberse cruzado en su vida la barbarie y la locura colectiva de mediados del siglo XX.

17 Duques de Medina Sidonia por aquellos entonces señores, entre otras muchas poblaciones, de San Juan del Puerto y sus inmediaciones, de ahí el afán de crear un puerto próximo a sus áreas de producción.

18 Archivo Municipal San Juan del Puerto (en adelante AMSJ), legajo 43. Primer Privilegio

19 Archivo municipal de San Juan del Puerto. Confirmación de los privilegios por Don Juan Claro Guzmán. Legajo 43. Todo el compendio de privilegios.

20 M.A. Ladero. Niebla, de Reino a Condado. Noticias sobre el Algarbe Andaluz en la Baja Edad Media (Discurso de Ingreso en la RAH), Madrid, 1992

21J.A. Mora. Huelva ilustrada. Historia de antigua y noble villa de Huelva. Sevilla, 1762, pp. 51 y 52. 
"Yo, D. Juan de Guzmán... quanto a lo que dezis que yo dixe que quería mandar prestar a los vecinos pescadores, o hombres de la mar, que de fuera de mi tierra y seńorío vinieren de nuevo a vivir, e poblar a ese mi lugar, con sus mujeres e casas, cada quatro o cinco mil maravedís a cada uno, e que yo mandé depositar el dinero que para ello fuese necesario en una persona abonada de ese consexo para que los dé a los tales vecinos que aí vinieren, porque más presto venga en nombre del cresemiento, e poblasón de ese mi lugar, e aya gente que ande en los navíos que agora e mandado hacer, a esto vos respondo que mandaré prestar a cada uno quatro mil maravedís, y que persona tal terná el dinero obligándose las personas a quien se prestaren de pagallos en tiempos de quatro ańos, e de hacer casa, e vińa según se contiene en el previllexo a cuio fuero e costumbre ese mi lugar es poblado". ${ }^{22}$

Esta clara vocación comercial y marítima va a generar en el espacio sanjuanero, en sus primeros siglos de existencia, numerosos lugares y símbolos con una significatividad muy especial. El carácter marismeño de su entorno, así como la existencia de un brazo de río en el mismo limes de la población, configurará un paisaje natural y humano ligado al agua, dotándole por ello de una idiosincrasia muy especial. Ello va a instituir una determinada forma de apreciación simbólica del espacio, donde la conjunción de diferentes tramas sociales y naturales generarán una identidad muy definida, dotándola de sentido. En este sentido, como apuntan Gupta y Ferguson ${ }^{23}$, estas ideas "recibidas" por medio de la interiorización cultural en la comunidad, tanto del espacio como del lugar, han configurado y continúan configurando la identidad pasada y presente.

La población sanjuanera de sus primeros siglos de existencia, va a crear una cosmogonía espacial a partir de los diferentes aprovechamientos del entorno, así como por las relaciones sociales que se establecerán para ello, generando una construcción simbólica del espacio con una significatividad muy concreta, donde cabrán creencias, rituales, valores, relaciones y un largo etcétera de elementos constitutivos de su Cultura, tal y como esgrime Gárate Castro ${ }^{24}$ :

22 Archivo de la Fundación Casa Medina Sidonia, legajo 736, en González Cruz, David: El puerto de San Juan en tiempos del Descubrimiento de América y la expansión atlántica. Artículo recogido en la obra Descubridores de América. Colón, los marinos y los puertos. Madrid: Editorial Sílex, 2012, pp. 201-244.

23 A. Gupta y J. Ferguson. "Más allá de la cultura. Espacio, identidad y las políticas de la diferencia”. En Antípoda no 7, 2008, pp 233-256.

24 L. A. Gárate. "Identidad y Patrimonio. Semántica espacial de la Alameda de A Guarda”. En Revista de Antropología Social, no 4, 1995, pp. 57-81. 
"El espacio se construye y adquiere sentido en la medida en que se le atribuyen significados que se relacionan con los valores, normas, creencias, intereses, prácticas, etc., de los actores protagonistas. En otras palabras, el espacio es expresivo (significante) y al mismo tiempo posibilita el desarrollo de acciones expresivas por parte de los grupos humanos; incita a la acción social, dotándola de intensidad emotiva y de dirección. Pero la acción social modela igualmente la carga denotativa y connotativa del marco físico en el que se desenvuelve. De ahí que debamos contemplar el condicionamiento como mutuo. Por un lado, la expresividad de la praxis social se contextualiza en un mareo espacial cargado de significados que restringen y acotan su potencialidad expresiva. Por otra parte, la misma praxis también modifica este marco al producir reajustes en los significados de los ámbitos espaciales".

Esta peculiar forma de apreciación y apropiación del medio, va a desembocar, en la creación de varios ámbitos simbólicos interconectados entre sí, pero cada uno de ellos con unas características definibles por sí mismos. Así, profesionales de diverso rango, relaciones de producción igualmente diferentes, y conexiones sociales muy específicas, van a marcar cada uno de estos ámbitos, definidos a partir de un sentido de pertenencia y de apego por un modo de vida concreto.

De todos los ámbitos, dos van a ser los que determinen al espacio viario, configurándolo de una forma peculiar. Así, el ámbito marismeño será un espacio de gran simbolismo aún hoy en día, sirviendo como motor de cohesión. La actividad salinera, la molinera, la de trasbordo de personal y mercancías a poblaciones cercanas, la pesca en las proximidades o sus cańos, así como la carpintería de ribera, serán algunas de las actividades las cuales tendrán cabida en este espacio ${ }^{25}$.

Aspectos realmente interesantes de este ámbito van a ser la adscripción profesional que se va a ir dando por generaciones, así como el modelo de ocupación del espacio viario. De esta forma, nos encontraremos con verdaderas sagas familiares ${ }^{26}$ las cuáles van a ir transmitiendo, de generación en generación,

25 J. C. Romero Villadóniga. Referentes patrimoniales e identitarios de San Juan del Puerto. Su cosmogonía marismeńa o la historia de un sentimiento. Tesis doctoral presentada en el Salón de Actos de la Facultad de humanidades de la UHU, el 10 de Octubre de 2015. En ella se recogen listados ingentes de personas vinculadas a este ámbito a lo largo de sus cinco siglos de historia, siendo un porcentaje de población muy representativo en el conjunto total de la población sanjuanera.

26 En la tesis anteriormente descrita es muy frecuente observar cómo se producen correlaciones familiares a lo largo del tiempo con unas mismas características sociolaborales, siendo muy representativo en el caso de los pescadores. 
no sólo técnicas y medios de producción ${ }^{27}$, sino que también organizará unas relaciones sociales específicas evidenciadas en los sistemas de pago por trabajos ${ }^{28}$ , las redes de solidaridad ${ }^{29}$, o los rituales marcados a golpe de crecida y bajada de la marea $^{30}$.

Igualmente, una análisis histórico del colectivo que compondrá este ámbito, nos habla de unas orientaciones espaciales muy definidas, localizándose las viviendas casi siempre en calles perpendiculares al río y en áreas muy próximas, albergando en ella a primos, tíos o abuelos, todos ellos con un denominador común, pertenecer a un mismo colectivo sociolaboral ${ }^{31}$.

El segundo de los ámbitos, el portuario, se va a configurar como el principal articulador del territorio sanjuanero. Hasta la propia disposición urbanística va a venir condicionada por su existencia, disponiéndose las calles perpendiculares (como en la actualidad) a las marismas y su brazo de río, al objeto de tener una buena comunicación con el principal centro de transporte del condado de Niebla. Igualmente, el principal eje de comunicación, donde va a confluir el poder religioso (iglesia) con el civil (edificios adminsitrativos), va a discurrir en perpendicular con el puerto, por las actuales calles Dos Plazas y Ríos ${ }^{32}$, lo cual es indicador del enorme grado de complejidad espacial al que se va a llegar, con una estructuración simbólica y real de los principales poderes fácticos, en una jerarquía perfectamente definida (religiosa-civil-económica).

Fuente de riqueza, pero también de conflicto, albergará en su seno actividades muy variopintas, así como relaciones sociales y visiones de vida, comportándose como un microcosmos donde la actividad organizada de carreteros, cargadores, estibadores, esparteros y toneleros convivirán con el duro mundo del transporte a

27 En los Libros de Protocolo suele encontrarse heredades como barcas o aperos, transmitiéndose por este medio de generación en generación.

$28 \mathrm{El}$ sistema de pagos por cuartillas a los molineros es un buen ejemplo de la complejidad relacional a la que se llegará en este ámbito, estando todo el proceso ritualizado y con una alta carga simbólica.

29 Resulta común encontrar en los legajos cómo la solidaridad no sólo alcanzaba al terreno profesional, sino también personal, compartiéndose viviendas y vivencias en torno a éstas.

30 Los ritmos de molienda aprovechando la bajamar, o la recogida de agua durante la pleamar, o la salida y llegadas de embarcaciones aprovechando la corriente del río Tinto, van a marcar no sólo un ritmo, sino también una percepción del espacio intrínsecamente ligada a éste.

31 Las relaciones familiares van a ser un elemento muy importante a la hora de la adscripción laboral, pues va a ser tónica común que los padres sirvan como oficiales o maestros, teniendo como ayudantes o aprendices a sus hijos, mezclándose la esfera laboral con la personal, lo cual es indicador de la enorme complejidad de la sociedad sanjuanera de la época.

32 A lo largo de la Edad Moderna, este eje va a ser el que experimente el trasiego de mercancías y personas, siendo la principal arteria de comunicación. No es casualidad que en una misma línea espacial se ubique la iglesia, los centros administrativos y el centro económico por excelencia, lo cual nos habla de una organización espacial muy compleja y perfectamente estructurada. 
bordo de urcas de gran tonelaje y otros barcos que jalonaban sus aguas de forma cotidiana.

Así pues, la proximidad al río y sus marismas, va a configurar en el sanjuanero atemporal, una especial visión del entorno, dotándole de significado y de simbolismo. Dentro de él, ritos, relaciones, sentimientos van a ir conformando una idiosincrasia que perdurará a lo largo del tiempo, convirtiéndose en rasgos identitarios actuales, difícilmente explicables si no es recurriendo a las relaciones que, tiempos atrás, se establecieron de forma cotidiana.

Gracias a la actividad de $\operatorname{archivo}^{33}$, podemos contar hoy en día, con ingente información acerca de los numerosos molineros, marineros, pescadores, carpinteros, etc, que han pasado de forma anónima por la historia sanjuanera, pero que han dejado una huella imborrable, una estela en la identidad colectiva de todos los sanjuaneros, aun no sabiéndolo ellos.

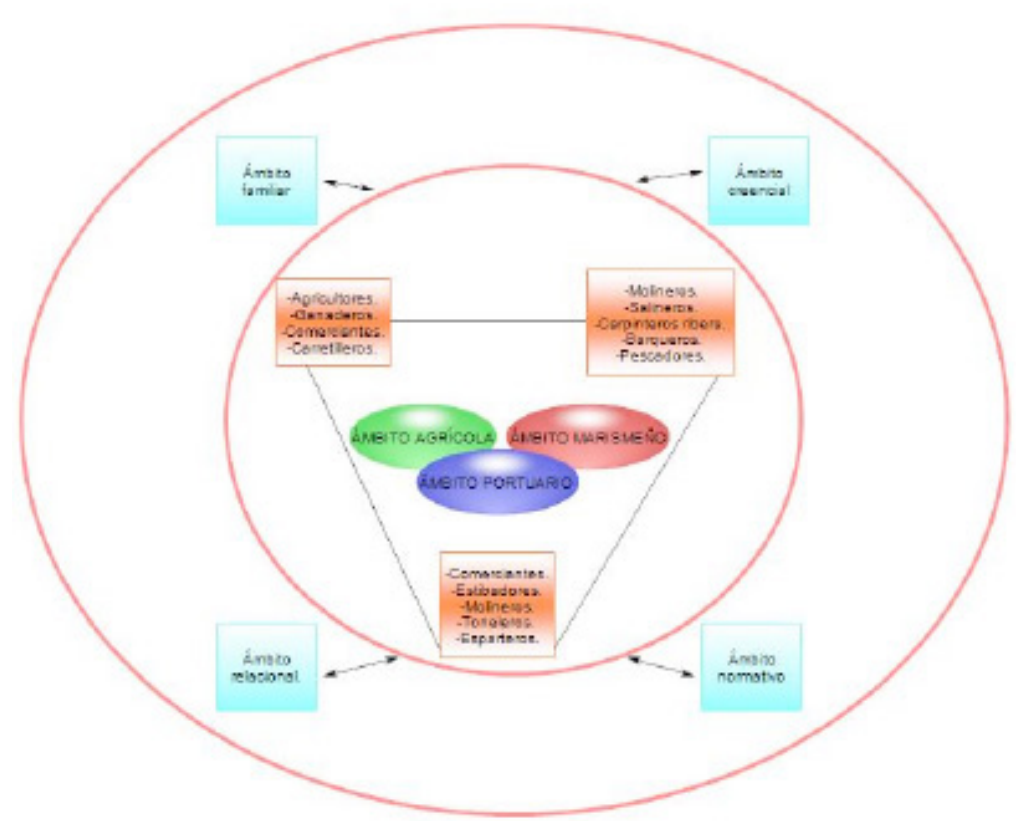

Fig. 1. Configuración profesional de cada uno de los ámbitos.

Fuente: autor

33 Los archivos municipales sanjuaneros, especialmente las Actas Capitulares y los censos ya a partir de mediados del siglo XIX, son fuentes realmente ricas en datos acerca de la composición de la sociedad de la época. 
Un día cualquiera. San Juan del Puerto ante los ojos indiscretos de ENSENADA.

A tenor de lo visto hasta ahora, queda fuera de toda duda las ligazones existentes entre la identidad sanjuanera y la cosmogonía natural que le rodea. Estudios como los de Pulido Bueno ${ }^{34}$ o Núñez Roldán ${ }^{35}$, así como otros artículos más $\operatorname{concretos}^{36}$, definen a la perfección la importancia económica del puerto en la configuración local. No obstante, para poder realizar una breve pincelada etnohistórica de sus habitantes a lo largo de su existencia, no son estos estudios los que nos puedan aportar gran cantidad de datos, debido a la escala en la que se mueven.

Por esta razón, se debe recurrir a la fuente documental primaria siendo, en este sentido, el Catastro de Ensenada, uno de los “informantes” más completos y complejos $^{37}$ existentes en los archivos municipales, permitiendo un bosquejo en toda regla de la sociedad sanjuanera, siendo ésta la razón por la cual se ha tomado como referente y se ha analizado en su integridad ${ }^{38}$.

A partir del análisis de sus fuentes documentales, podemos tomar una visión a primera vista, distorsionada de la realidad sanjuanera, ya que un análisis cuantitativo refleja una sociedad eminentemente ruralizada ${ }^{39}$ Sin embargo, esta cifra no debe empañar en ningún momento la importancia de las actividades ligadas al río Tinto, las cuales son especialmente representativas, ya que todas tendrán sentido de ser a partir de la conjunción con las actividades portuarias. Igualmente, no debemos olvidar la importancia de la actividad marinera y su relación con la agricultura, ya que San Juan del Puerto y su entorno tiene una producción cerealera gracias a la posibilidad de exportación de dichas mercancías por medio del puerto ${ }^{40}$.

34 I. Pulido. La tierra de Huelva en el Antiguo Régimen 1600-1750. Un análisis socioeconómico comarcal. Huelva: Diputación Provincial de Huelva, 1988.

35 F. Núńez. En los confines del reino. Huelva y su tierra en el siglo XVIII. Sevilla: Universidad de Sevilla 1992.

36 M. J. De Lara. "Comercio agrí́cola en la ría del Tinto: San Juan del Puerto a mediados del siglo XVIII”. En D. González (ed): Cinco siglos de historia de la villa de San Juan del Puerto (14681992). De la tradición marinera al proceso de industrialización. San Juan del Puerto: Imprenta Beltrán, 1992, pp. 123-146.

37 Como expone Francisco Núnez Roldán en su obra "En los confines del Reino", el Catastro de Ensenada parte por ser una fuente de conocimiento muy precisa para las poblaciones donde se conservan, no solo las respuestas generales, que a la sazón no son sino pequeños extractos documentales, sino las seriaciones completas incluyendo tanto las fincas seculares como las eclesiásticas

38 AMSJP. Legajos 493 y 494. En ambos se recogen la lista de fincas seculares, eclesiásticas, así como una copia de las Respuestas Generales que se enviaron.

39 Núñez Roldán, En los confines...pp. 113. San Juan del Puerto durante el momento de la elaboración del Catastro de Ensenada, es un pueblo eminentemente agrícola, al vivir de esta actividad aproximadamente el $79 \%$ de la población, cifra ligeramente inferior a otras poblaciones del interior, dedicándose a la producción del cereal de secano, la vid, el olivo y los frutales,

40 De Lara, Comercio agrícola en la ría del Tinto: San Juan del Puerto a mediados del siglo 
De los 403 vecinos censados en el Catastro de Ensenada, 350 van a estar englobados en el ramo agrícola, siendo usual la tenencia de pequeñas parcelas destinadas a la autosuficiencia doméstica, algo muy frecuente en la zona ${ }^{41}$. No obstante, muchos de estos jornaleros van a simultanear sus actividades con las que, por aquellos entonces, se desarrollaba en las marismas, tales como la molienda de cereal o la carga y descarga de embarcaciones como es el caso de Gaspar González, panadero al tiempo que marinero matriculado ${ }^{42}$, de ahí que los estudios llevados a cabo tengamos que ponerlos en cuarentena al no tomar este dato en consideración. .

De esta forma, el colectivo de marineros y pescadores ${ }^{43}$ va a contar con una representación realmente importante, no pudiéndose realizar una diferenciación de ambos por medio de los registros al haber una mezcla de ambos en los documentos ${ }^{44}$.

Curiosamente, la población va a contar sólo con un patrón de barco matriculado Francisco Carrillo, lo cual resulta paradójico si tenemos en cuenta que se registran varias embarcaciones tanto de pesca como de pasaje. En lo referente a sus emolumentos resulta ser de los profesionales mejor pagados de la población: ${ }^{45}$

Francisco Carrillo, patrón de barco cassado, tiene un hijo marinero matriculado que se expressará en su lugar, otro menor y una hixa utiliza de jornal al dia cinco reales y quartillo de vellon de que corresponden a los ciento y ochenta que deven cargarse a lo Personal novecientos cuarenta y cinco reales vellon al año

Este aspecto no resulta extraño, ya que se evidenciará como algo normal que el colectivo dedicado a labores marinas y pesqueras perciba unas rentas muy superiores a las de otros ramos. Así, mientras que un jornalero venía teniendo una renta de 420 reales de vellón al año, los marineros van a obtener unos dividendos de 630 reales de media ${ }^{46}$, cifra ostensiblemente superior.

\section{XVIII.. pp. 138}

41 Durante esta época se constata la existencia de un parcelario extremadamente fragmentado y con diversas calidades del suelo, lo cual es un aspecto a tener en cuenta, ya que una excesiva parcelación indica una escasa capacidad de innovación por parte de sus dueños al necesitarse una alta productividad para la obtención de beneficios tras superar los costes productivos.

42 AMSJP. Legajo 494. Folio 16

43 El Catastro de Ensenada no delimita los pescadores de los marineros, por lo que no tenemos elementos de diferenciación que podamos utilizar. Dentro de este capítulo tendríamos que diferenciar entre patrones de barco y marineros "matriculados", lo cual no quiere decir que sean todos los que realmente practican esta actividad.

44 Núńez Roldán diferencia entre marineros como grupo socioprofesional con rasgos propios, y la pesca como una actividad productiva. En nuestro caso, debido al estado actual de la investigación, aún no podemos hacer esa diferencia, de ahí que hablemos de marineros y pescadores de manera indiferente.

45 AMSJP. Legajo 494. Folio 37

46 Las medias serían calculadas a razón de 3,5 reales de vellón al día de suelo por un promedio de 180 días de trabajo. El promedio de días de trabajo va a aplicarse a casi todos los profesionales 
Espacialmente este grupo se va a concentrar en dos calles cercanas a la zona de marismas, como son la calle Esparteros y la Ribera del Río, las dos calles mejor comunicadas con el puerto comercial, así como las dársenas naturales donde amarrar o reparar embarcaciones. Ello nos informa de una organización espacial donde todo el entramado viario y relaciones girará a partir de la ubicación del puerto. Con casas de dos cuerpos y una planta, solían tener unas 13 varas de fachada y 20 de fondo, van a ser ligeramente superiores a las de otros colectivos ${ }^{47}$.

Curiosamente, a pesar de tener rentas superiores a la media de la población, pocos serán los que posean alguna propiedad más que la casa o la embarcación ${ }^{48}$, aspecto éste que se repite en innumerables poblaciones pesqueras atemporales, al no necesitar como instrumentos de producción más que los propios de sus artes, frente a profesionales como los agricultores, ávidos de tierras para el desempeño de su labor.

La lista de propietarios de embarcaciones va a resultar numerosa, presentando un perfil parecido. Normalmente constaban de una vela, trece codos de quilla y capacidad de treinta quintales, reportando una media de cien ducados al año. Tales van a ser los casos de Francisco Prietto ${ }^{49}$, Francisco Méndez ${ }^{50}$, Joseph de Cardenas ${ }^{51}$, Sebastián Perez ${ }^{52}$, Antonio Sanchez ${ }^{53}$ y Pedro Alonso ${ }^{54}$, todos ellos igualmente propietarios de casas localizadas principalmente entre las calles Esparteros y Frontera del Río, en las proximidades al puerto. Este mundo masculinizado va a contar entre sus filas, con una mujer, Catalina Ignazia ${ }^{55}$, viuda de marinero afincada en la calle Esparteros, lo cual no es sino meramente anecdótico y que nos introduce de lleno en la mentalidad patriarcal de la sociedad de la Edad Moderna.

recogidos en el Catastro.

47 En comparación con los carreteros o los arrieros (9-10 varas de frente por 16 de fondo) casas pequeñas, pero en relación a los jornaleros eran de similares características

48 De todos los marineros registrados, tan solo uno va a tener tierras en propiedad, Juan de los Reyes (Legajo 493, folio 462, el cual va a tener dos casas en la calle Esparteros de un tamaño superior a las casas anteriormente descritas ( 2 cuerpos con 13 varas y media de fachada y 44 de fondo con corral, la primera y 3 cuerpos con 11 varas y tres cuartos de fachadas y 29 varas de fondo, la segunda), así como tierras de octava clase en la vega de San Andrés , 3 fanegas de $8^{a}$ clase en La Luzera, próximo al convento de la Luz en Lucena del Puerto y tierras de secano de segunda clase en el paraje el Burrilo, próximas al actual puerto.

49 AMSJP. Legajo 493. Folio 174

50 AMSJP. Legajo 493. Folio 180

51 AMSJP. Legajo 493. Folio 407

52 AMSJP. Legajo 493. Folio 695

53 AMSJP. Legajo 494. Folio 24

54 AMSJP. Legajo 494. Folio 24. Al igual que en el caso anterior, no se han encontrado todavía muchos datos acerca de este marinero dueño de un barco de pesca. Quizás a medida que podamos profundizar en la investigación lleguemos a vislumbrar más aspectos de ambos.

55 AMSJP. Legajo 493. Folio 98 
Al margen de las embarcaciones de pesca, también los documentos arrojan a la luz otras dos tipologías muy comunes en la época, la barca de pasajes y la de tráfico de mercancías internacional. Con respecto a la primera, su dueño, Rodrigo Pérez ${ }^{56}$, reconoce una utilidad de 961 reales, cifra nada despreciable para la época $^{57}$. La última de las embarcaciones registradas en el Catastro de Ensenada va a ser propiedad de José Agustín García de Valladares ${ }^{58}$, poseedor de gran cantidad de tierras y fincas rústicas repartidas a lo largo de la población, así como administrador de aduanas, traficante de mercancías variadas, siendo el único dueño de un barco de viajes por alta mar, reportándole 4000 reales al año.

Un aspecto realmente importante y sintomático del apego existente entre colectivo con su medio natural, va a venir de la mano de la adscripción familiar a determinadas actividades, como la marinería o la pesca, produciéndose incluso hasta una jerarquización entre los padres (patrones o dueños de los barcos) y los hijos (pescadores o marinería en general). Familias como las de Francisco Prieto ${ }^{59}$, con cinco hijos matriculados en el ramo de la pesca ${ }^{60}$, van a ser ejemplos comunes de una cotidianeidad fundamentada en el apego, la tradición y la posesión de instrumentos de producción. Juan Manuel Prieto, Francisco de Paula Prieto, Antonio Joseph Prieto, Joseph de la Cruz Prieto y Diego Diaz ${ }^{61}$ obtendrán por sus servicios unas rentas aproximadas de 630 reales de vellón cada uno al año, así como vivirán en la casa paterna de Francisco Prieto. Otras familias, como

56 AMSJP. Legajo 493. Folio 653. En el registro consultado, el personaje en cuestión figura como "barquero", diferenciándolo de los marineros y pescadores. Resulta extraño que no se le conozca otra propiedad, ya que, en relación con la remuneración de la mayor parte de las profesiones, cobra casi un tercio más que marineros y dos tercios que jornaleros.

57 AMSJP. Legajo 493. Folio 653 'Posee un barco pasagero de doze codos de quilla, el que por el permiso le produze de utilidad revajado su arrendamiento al ańo nuevecientos sesenta y un reales de vellon"

58 José Agustín García de Valladares va a ser, durante estos momentos la persona más influyente y con más recursos de la población. De condición noble y letrada, ostentará el cargo superior de gestión y administración portuaria, al tiempo que será traficante de diversas mercancías y terrateniente latifundista. El Catastro de Ensenada, en su libro de Fincas Seculares, va a dedicar doce páginas a comentar las propiedades del que, sin duda alguna, va a ser el principal hacendado de la zona.

59 AMSJP. Legajo 494. Folio 24

60 AMSJP. Legajo 494. Folios 23-24 "Francisco Prieto Dueño de dos barcos pescadores marinero matriculado cassado tiene cinco hixos mayores matriculados que con el padre se explicaran en su respectiva classe con el jornal que por marineros matriculados les corresponde tiene tambien tres hixas utiliza e cada uno de dichos dos barco quinientos y cincuenta reales vellón que a los dos les corresponde mily cien reales de vellon al año"

61 AMSJP. Legajo 494. Folios 37-39. Aunque no se corresponda con los apellidos, cosa normal en esta época debido a la aún precariedad de los registros, Diego Díaz es hijo de Francisco Prieto, como lo atestiguan las fuentes: "Diego Díaz, marinero matriculado, soltero comprendido en la familia de Francisco Prieto su padre, utiliza de jornal al día tres reales y medio de vellón de que corresponden a los ciento y ochenta dias que deben cargarse a lo personal según reales

órdenes seiscientos y treinta reales vellón al año". 
las de Josseph de Cárdenas ${ }^{62}$, con sus dos hijos (Francisco Ramos y Rodrigo de Cardenas), o las de Antonio Massias, Francisco Carrillo o Catalina Ignacia no hacen sino hablarnos de la impronta imborrable que va a tener este medio en la conformación de la identidad sanjuanera, tanto comunitaria como personal.

La importancia cuantitativa y cualitativa de este grupo está pues, fuera de toda duda, siendo fuente de riqueza, así como de conflicto en el seno de la sociedad sanjuanera, necesitándose en no pocas ocasiones, la intervención de las autoridades a la hora de la postura del pescado, como queda bien atestiguado en las Actas Capitulares de $1774^{63}$, procediéndose a regular la venta en los siguiente términos:

"En la villa de San Juan del Puerto, en veinte y tres dias del mes de octubre de mil setecientos setenta y quatro años, los Señores Corregidores Justicia y Regimiento de ella que avajo firmaran, estando juntos en su sala capitular como lo tienen de uso y costumbre, teniendo presente la necesidad que ai de proveer de un Señor Capitular que asista todas las mañanas en la Rivera del Río, a poner postura de pescado acordaron. Que por la semana vayan los Señores Regidores y Diputados de Abastos a dicha rivera a el salir el Sol y estén en el ynvierno hasta las ocho, y en verano hasta las siete y pongan las posturas que se ofrescan y eviten las disputas y discordias que sobrebengan,..."

Otro colectivo que va a establecer una especial relación con el entorno marismeńo va ser el de los molineros. De esta forma, en las Respuestas Generales ${ }^{64}$, concretamente en la número 17 , se contesta respecto a la existencia de molinos mareales en la zona:

"Que ay quatro molinos harineros de agua y dos tercios de otro, los dos de seglares y producen quatro mil y treinta y seis reales.

Dos molinos y una venta parte de otro de Beneficial que producen tres mil ochocientos setenta y nueve reales once maravedies y un tercio.

El otro medio es Patrimonio y produce del año novecientos treinta y siete reales".

62 En la lista de marineros matriculados normalmente, los hijos menores o solteros, son adscritos a la familia de su padre. En el caso de los hijos de Joseph de Cardenas, Francisco Ramos (AMSJP. Legajo 494. Folio 38) es el único que tiene apellidos distintos al resto de los hermanos, pero, al igual que el caso anterior, el registro indica que vive en la familia de su padre de manera clara.

63 AMSJP. Legajo 19, repitiéndose la conflictividad en 1779.

64 AMSJP. Legajo 494. Extractos a las Respuestas Generales. Única Contribución. Respuesta 17. 
Tabla 1. Relación de marineros matriculados, estado civil y rentas asignadas según el Catastro de Ensenada

\begin{tabular}{|l|l|c|}
\hline \multicolumn{1}{|c|}{ Nombre y apellidos } & Estado civil & Rentas \\
\hline Francisco Carrillo & Casado & 945 reales \\
Juan González; Antonio Massías González; Francisco & & 630 reales \\
Prieto; Rodrigo Pérez; Pedro Díaz; Joseph de Cárdenas; \\
Gaspar González; Sevastián Pérez; Juan de los Reyes; \\
$\begin{array}{l}\text { Ygnacio de Acosta; Joseph Revollo; Francisco Santos; } \\
\text { Benito Rebollo; Juan Carrillo; Pedro Daza }\end{array}$ & & \\
\hline $\begin{array}{l}\text { Joseph Ysidro Díaz; Joseph de Mora; Francisco Vallés; } \\
\text { Ygnacio Acosta }\end{array}$ & Viudos & 630 reales \\
\hline $\begin{array}{l}\text { Francisco Ramos; Diego Díaz; Dionicio Carrillo; Phelipe } \\
\text { de la Cruz; Juan Manuel Prieto; Francisco de Paula Prieto; } \\
\text { Rodrigo de Cárdenas; Antonio Joseph Prieto; Joseph de } \\
\text { la Cruz Prieto; Jerónimo Méndez; Pedro Alonso; Estavan } \\
\text { Valles; Francisco Pérez; Francisco Páez; Francisco Martín } \\
\text { Prieto; Estaban Valles; Pedro Alonso; Miguel Sánchez; } \\
\text { Antonio de los Santos Prieto }\end{array}$ & & \\
\hline
\end{tabular}

Elaboración propia.

A pesar de la enorme importancia para la economía local, curiosamente las Respuestas Generales no reconocen ningún molinero, lo cual resulta normal teniendo en cuenta que muchas veces era una actividad ligada a tareas agrícolas, pudiendo encargarse por aquellos entonces hasta incluso los propios panaderos a tal efecto. El único arrendador reconocido, Juan Garrido Lovato ${ }^{65}$, maestro tonelero con dos hijos aprendices del mismo oficio, percibirá unas rentas de 794 reales de vellón anuales, cifra muy elevada para las rentas de la época.

Con respecto a los otros tres molinos, éstos van a estar en manos del principal hacendado de la época Josseph Augustin Garcia Valladares ${ }^{66}$, así como a dos vecinos de la población de Trigueros ${ }^{67}$. Igualmente, una mujer va a ser también propietaria de uno de los molinos harineros sanjuaneros Cathalina Benítez ${ }^{68}$ :

65 Resulta curioso que sólo aparezcan los arrendadores de los molinos y no los molineros en esta relación. Quizás por tratarse de un documento con intereses fiscales interesarían sólo aquellos contribuyentes que pudieran ser utilizados para el pago de impuestos.

66 AMSJP. Legajo 493. Folio 292.

67 Fernando de Campos AMSJP. Legajo 493. Folio 807 Maria Ysidora AMSJP. Legajo 493. Folio 902

68 AMSJP. Legajo 493. Folios 87-88. 
"Posee un molino harinero nombrado la Hazeña en el Río, distante de estta población un tiro de piedra muele con tres heridos burros con el agua de las corrientes del expresado Río"

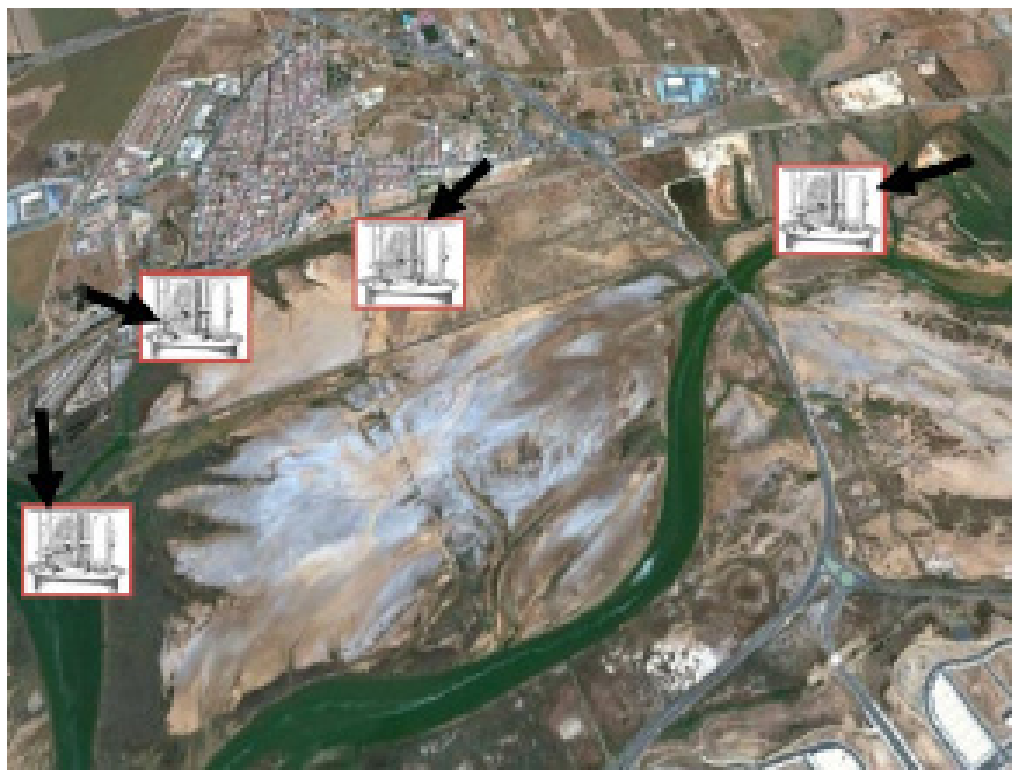

Fig. 2. Ubicación de los cuatro molinos próximos a la población. Fuente: autor

Del mismo modo que marineros y molineros, un tercer colectivo directamente ligado al río Tinto y su entorno estará compuesto por los carpinteros de ribera. Por estas fechas, San Juan va a contar con siete maestros carpinteros, cuatro de lo prieto $^{69}$ y tres de lo blanco ${ }^{70}$, disponiendo rentas de 900 reales de vellón al año, lo cual hace ver su importancia en el conjunto de la población. Estas elevadas rentas las complementarán con el comercio de mercancías ${ }^{71}$, reportando otros 1460 reales, convirtiéndose así en uno de los gremios mejor valorados.

69 De todos los carpinteros de lo prieto registrados, cuatro van a engrosar la fila de los maestros y otros cuatro la de aprendices. Entre los primeros están Miguel García, comerciante de maderas, Antonio García, Simón Sánchez y Manuel de Aquino. El segundo grupo lo compondrán Joseph Rodríguez, Joachin de Santa Ana, Joseph Rodríguez y Antonio Garcia. (AMSJP. Legajo 494. Folios 29-30).

70 Los carpinteros de lo blanco van a ser inferiores en número a los de lo prieto. Van a ser tres maestros los registrados en el Catastro de Ensenada (Rodrigo de Cardenas, Francisco de Cazares Valle y Joaquín de Carmona), mientras sólo va a comentarse la existencia de un aprendiz, Joseph de Cazares (AMSJP. Legajo 494. Folios 27-28)

71 Miguel García y Francisco Cazares Valle, van a ser los únicos comerciantes autorizados a la venta de materiales de carpintería, estando dedicado uno para la carpintería de lo prieto y otro para lo blanco. (AMSJP. Legajo 494. Folio 25) 
$\mathrm{Al}$ igual que en los casos anteriores, la adscripción profesional por parte paterna será manifiesta, siendo los aprendices hijos de los maestros, como le ocurrirá a la familia de Miguel García ${ }^{72}$ carpintero de lo prieto afincado en la calle Huelva, con posesiones repartidas por toda la población y tierras y ganado en las afueras. Su hijo, Antonio García, vendrá recogido en el listado de carpinteros de lo prieto con una asignación anual de 540 reales de vellón, lo que vendría a suponer una cantidad de unos 3 reales diarios de sueldo (180 días de trabajo $)^{73}$. Otros casos, como Antonio García y su hermano Miguel $^{74}$, tendrán igualmente a sus hijos ${ }^{75}$ como aprendices, informando así de cómo la tradición articula todo el entramado vital de la población sanjuanera en esta época.

Cobradores de aduanas, así como "alcaldes de la mar", serán cargos administrativos igualmente unidos al entorno marismeño. Lo más llamativo será el proceso de elección de los mismos, siendo las autoridades ducales quienes impondrán a su candidato, lo cual informa de relaciones de poder perfectamente establecidas y consensuadas por todos. Tal será el caso que aparece registrado en las actas capitulares de $1766^{76}$ donde todos los miembros del cabildo acuerdan aceptar la designación de Santiago Vasquez como nuevo Alcalde de la Mar.

Comerciantes, traficantes de tocinos, carretilleros, estibadores, esparteros, y un larguísimo etcétera de profesionales ligados al río completarán una ingente lista de familias dedicadas por completo al aprovechamiento de este preciado entorno. Toda una heterogeneidad productiva pero con un denominador común, una misma apreciación simbólica del espacio.

Todo este entramado simbólico responde a un apego, a un mayor o menor acercamiento del individuo respecto de su entorno ambiental y social. En cuanto

72 AMSJP. Legajo 493. Folio 569.

73 El Catastro de Ensenada contempla en el caso de los profesionales ligados a actividades comerciales, o liberales, incluyéndose en este ramo los marineros, una renta anual a partir del sueldo medio percibido en un día, durante 180 días al año. Se trata, por tanto, de una simple estimación a efectos fiscales que orientan de las retribuciones de los colectivos recogidos en el documento.

74 AMSJP. Legajo 494. Folio 28.

75 AMSJP. Legajo 494. Folio 29 Joseph Rodríguez y Joachin de Santa Ana

76 AMSJP. Legajo 18.Actas capitulares (acuerdos del 13/4/1766) En la villa de San Juan del Puerto, a treze dias del mes de Abrill de mill setecientos sesenta y seis años, ante los señores cavildo, Justicia y Regimientto de esta, que abaxo firmaran, se presento Santiago Vasquez vesino deella, con una probicion del Excmo Señor Duque de Medina Sidonia, mi Señor, firmada de su letra, y refrendada de Don Santiago Saez, su daza en Madrid a veinte y cinco de Marzo proximo passado; en que es servido nombrarle por Alcalde de la Mar y esteros del termino y jurisdicción de esta villa.

$Y$ vista por sus ministros, obedeciendola, como la obedecen con el respecto y acatamientto devido, y en su obedesimientto el dicho Santiago Vasquez pueda usar y use dicho empleo en la forma que su Excelencia manda, y que se le guarden los fueros y preheminencias, que como tal Alcalde de la Mar le tocan y pertenecen, en cuya virtud se admitieron sus mercedes por tal; y que de este recevimiento serremita el devido testimonio de su Excelencia, y asi lo acordaron y determinaron doy fee.

Joseph Muños, Diego de los Reyes, Ignacio Bueno, Juan de Fuentes, Juan Sanchez. 
a las relaciones que se establecen entre ellos y con sus familias, es un todo complejo que no hace sino hablarnos de una realidad múltiple la cual, a su vez afecta de forma compleja a la identidad sanjuanera a lo largo del devenir histórico.

¿Qué ES LO QUe QUeda DE TODO ELlO? LA INFLUENCIA DEL TIEMPO EN LA CONFORMACIÓN DE LA IDENTIDAD ACTUAL.

La influencia que ha ejercido esta peculiar apreciación del territorio en la idiosincracia sanjuanera continúa hasta nuestros días aunque de una forma diferente. Los problemas de contaminación ambiental ${ }^{77}$ por un lado, así como el desarrollismo de las últimas décadas del siglo pasado, provocó un gradual pero inexorable abandono de las relaciones productivas que se habían ido dando en los últimos siglos. No obstante, aún así, muchos rasgos que confrman la identidad sanjuanera se han visto inalterados desde tiempos remotos.

A nivel espacial, San Juan conserva aún una herencia disposicional proveniente de tiempos atrás, cuando el puerto era el principal organizador de la población. Así, todo el entramado urbano de los siglos XVII y XVIII mantiene el mismo trazado, con calles perpendiculares a las áreas de carga y descarga y con acceso orientado a las marismas. Ello genera una unión simbólica entre el entorno natural y el humano, al ser percibido como una continuidad de la población, integrándose espacialmente al tiempo que sentimentalmente, pues en esos espacios se desarrollarán numerosas relaciones y otros ritos con sentido comunitario. Las nuevas fases constructivas, algunas de ellas segregadoras del espacio húmedo, sirven como contraste de dos modos diferentes de interpretar la ocupación del territorio $^{78}$.

Esta peculiar ocupación espacial incide de forma directa en los espacios públicos $^{79}$, así como las relaciones que se establecen en ellos. Las plazas principales, así como los principales lugares de ocio ${ }^{80}$ se encuentran ubicados en las proximidades a las marismas, sirviendo como área de conexión identitaria entre los ciudadanos.

Rituales de quedadas, juegos y charlas infantiles y adolescentes, no van a ser sino formas de reforzar el sentimiento comunitario, quedando más aislados los individuos de las zonas periféricas modernas, asumiendo un rol pasivo en la

77 Deterioro provocado por una progresiva colmatación del brazo de río la cual hizo impracticable la navegación por la zona, así como por el proyecto de desecación de 1912 que rompió virtualmente la marisma mediante la creación de un muro de contención de aguas, pero sobre todo debido a la implantación en los años 60 de fábricas pesadas en las proximidades al río que desembocó en la muerte del mismo.

78 La coexistencia entre población sanjuanera asentada desde varias generaciones frente a otra foránea, ha diluido en parte el sentido de pertenencia así como el apego que trae consigo.

79 H. Lefevre. La production de l'espace social , Barcelona: Anthropos,, 1974.

$80 \mathrm{~J}$. Ros. Estudi sobre la capacitat ecológica de la regió metropolitana de Barcelona. Barcelona: Mancomunidad de municipios del área metropolitana de Barcelona, 1992. 


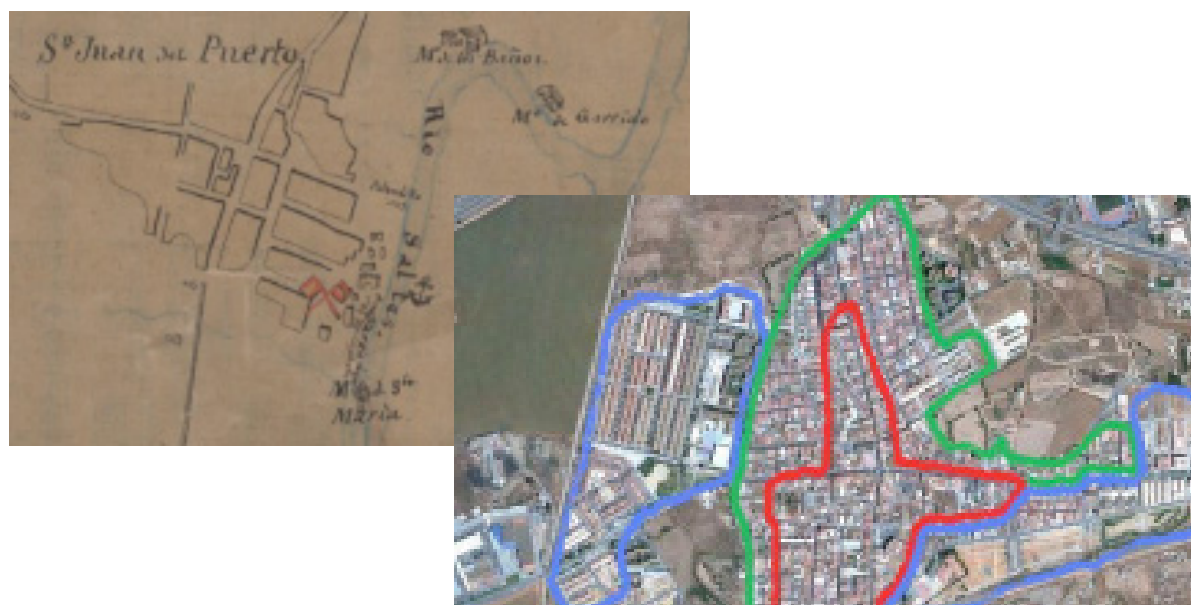

Fig. 2. Planimetría sanjuanera a mediados del siglo XIX. A la derecha, etapas del crecimiento de la población.

Fuente: autor

configuración social del paisaje, generando así, una doble tipología de ciudadanía: la más próxima a las marismas donde desarrollan actividades sociales las cuales recuerdan las de tiempos pasados y donde la memoria ${ }^{81}$ juega un papel destacado, al ser aglutinador del colectivo, frente a otro sector de la población más desligado y con visiones diametralmente opuestas, concibiendo el entorno como un área habitacional donde las relaciones sociales quedan en un segundo plano en algunas ocasiones.

Del mismo modo, otro elemento identitario que conforma al sanjuanero y su espacio viene determinado por la composición de su heráldica y monumentos. En casi todas las plazas con cierta relevancia, la aparición de elementos marineros tales como barcos, todos ellos con tipología definidas de la zona, en cierto modo similares a los de la heráldica, refuerza aún más el espíritu colectivo, asociándose no sólo con un lugar de ocio, sino con una forma de vida pasada la cual es rememorada con relativa frecuencia. No es casualidad que dichos monumentos y elementos representativos se ubiquen en espacio públicos con cierta importancia simbólica. Constituyen un alegato visual a una pauta identitaria común en la población, una forma de construir el colectivo a partir de una idea colectiva.

Otro referente identiario que va a indicar esta relación de apego, va a expresarse a partir del empleo del espacio en los tiempos libres. Todas las festividades y celebraciones con cierta solera en la población, se van a celebrar en áreas de marismas o proximidades. Así, festividades como la de San Juan Bautista,

81 Halbwachs. Fragmentos de la Memoria colectiva... 
carnavales, Día de Andalucía, etc, se desarrollan en contextos de unión entre el espacio viario y el natural, en zonas de parques los cuáles conectan ambas áreas, en desdeño de otras más amplias y quizás menos molestas para sus vecinos. Dichos festejos tienen la continuidad de los celebrados en el siglo XIX con motivo de la Degollación de San Bautista, patrón de la feligresía, en los mismos contextos, lo cual no es sino un signo de continuidad en la apreciación de dicho lugar. Del mismo modo, la mejora de las instalaciones portuarias, hoy convertidas en áreas de esparcimiento de propios y extraños, a conservación de las salinas, la puesta en valor del antiguo puerto primigenio ${ }^{82}$, la creación del Centro de Interpretación, no hace sino informar acerca de un proceso de revalorización del entorno húmedo y con ello, un nuevo acercamiento a un entramado de lugares los cuales tienen una significatividad muy especial tanto para los adultos, como para la población más infanti ${ }^{83}$.

Como espacios lúdicos ${ }^{84}$, esta reificación de los lugares naturales sanjuaneros ha generado una vuelta hacia el río y su entorno, convirtiéndose en espacio de con-vivencia donde los lazos grupales, intra e inter generacionales, se refuerzan a partir de un denominador común, un sentimiento propio con una especial idiosincracia plasmada en ritos, ritmos y creencias.

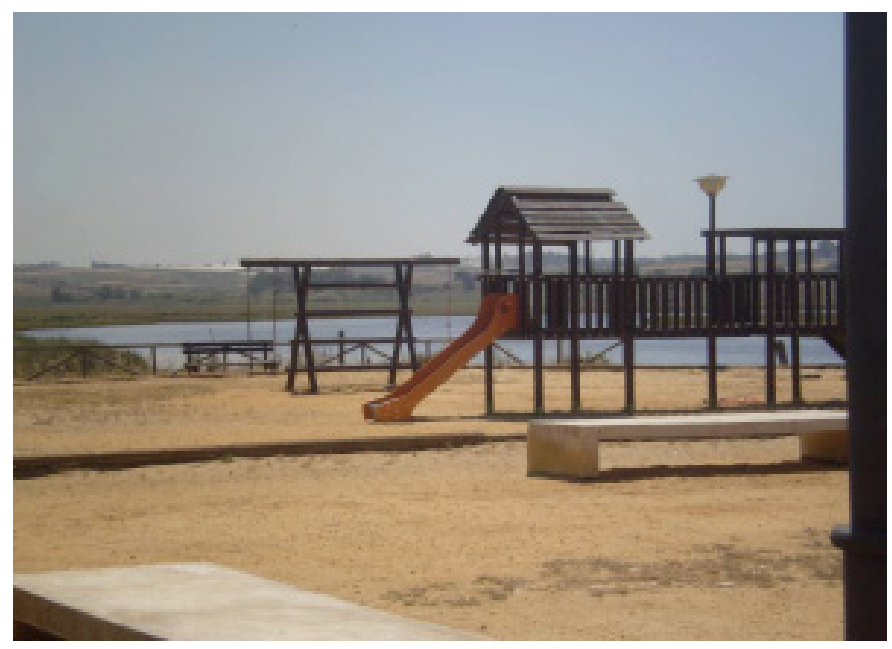

Fig. 2. Un pueblo que vuelve a mirar a su río. Fuente: autor

82 Gracias a la intervención arqueológica del equipo de trabajo del Catedrático Dr. Juan Campos Carrasco, poniéndolo nuevamente en valor patrimonial.

83En la tesis doctoral anteriormente mencionada, se procederá a la realización de un estudio acerca de la impronta del lugar en edades infantiles, alcanzándose resultados muy interesantes al poder establecer la correlación entre el esquema de espacio vivido en edad infantil con los referentes identitarios de la población.

84 T. Vidal y E. Pol. "La apropiación del espacio: una propuesta teórica para comprender la vinculación entre las personas y los lugares”. En Anuario de Psicología, vol 36, nº 3, pp 281-297. 
A MOdo De CONCLUSIÓN. ZARPANDO DEL LUGAR RUMbo PUERTO IDENTIDAD.

Que la identidad sanjuanera se nutre, entre otras fuentes, del entorno marismeño queda fuera de toda duda. El análisis etnohistórico a lo largo de sus primeros cinco siglos de existencia, nos habla de un mundo estructurado a partir de una apreciación del espacio ,por medio del apego, que conllevará ritos, relaciones y formas de entender la vida las cuales se irán transmitiendo de generación en generación.

Esta transmisión va a ir gestando, en la memoria atemporal colectiva, rasgos específicos los cuales se convertirán en características identitarias, aportando genuinidad al proceso.

Dichos rasgos han perdurado hasta la actualidad, a pesar de haberse perdido la concepción original con la que se concebía el medio marismeño, habiendo pasado de ser un espacio productivo a otro de disfrute y ocio, con las consiguientes transformaciones de apreciación que ello conlleva.

Ritos sociales, relaciones, formas de entender el momento lúdico, no son sino manifestaciones cuyas raíces se hunden en los primeros siglos de existencia del pueblo, sirviendo el puerto y su entorno como aglutinador de todo ello.

Al fin y al cabo, estamos hablando de sentimientos ${ }^{85}$, es decir, emociones las cuales han sido interiorizadas culturalmente en el seno de las comunidades y que generan formas muy específicas de apreciación de la vida.

Para el caso que nos ocupa, el sentimiento por un entorno, por sus raíces históricas, han generado, a modo de prospectiva, un planteamiento futuro de recuperación y potenciación de esas señas de identidad que dotan de homogeneidad a la colectividad frente a esta macdonalización de la sociedad.

85 D. Le Breton. "Por una antropología de las emociones". En Revista Iberoamericana de Estudios sobre Cuerpos, Emociones y sociedad. Buenos Aires, 2012 pp. 69-79. 